\title{
Potential therapeutic mechanism of genistein in breast cancer involves inhibition of cell cycle regulation
}

\author{
LING ZHANG ${ }^{1}$, BO YANG ${ }^{2}, \mathrm{KE} \mathrm{ZHOU}^{3}, \mathrm{HUA} \mathrm{LI}^{2}, \mathrm{DONG} \mathrm{LI}^{2}, \mathrm{HUI} \mathrm{GAO}^{2}$, \\ TAO ZHANG ${ }^{2}$, DONG WEI ${ }^{2}$, ZHIHUI LI ${ }^{1}$ and YONG DIAO ${ }^{1}$ \\ Departments of ${ }^{1}$ Radiotherapy and ${ }^{2}$ Oncology; ${ }^{3}$ PET-CT Center, Chengdu Military General Hospital, \\ Chengdu, Sichuan 610083, P.R. China
}

Received November 26, 2013; Accepted May 29, 2014

DOI: $10.3892 / \mathrm{mmr} .2014 .2907$

\begin{abstract}
Genistein can prevent tumorigenesis and reduce the incidence of diseases that are dependent upon estrogen. Previous research, however, has shown that genistein can also increase the risk of breast cancer. Thus, the aim of the present study was to investigate the mechanism underlying the effect of genistein in breast cancer and to determine whether genistein produces a therapeutic effect or promotes the development of breast cancer. Gene microarray data obtained from three samples treated with alcohol (control group), three samples treated with $3 \mu \mathrm{mol} / 1$ genistein and three samples treated with $10 \mu \mathrm{mol} / \mathrm{l}$ genistein for $48 \mathrm{~h}$, were downloaded from the Gene Expression Omnibus database. Analysis of the differentially expressed genes (DEGs) and functional enrichment in the two genistein groups was performed. The interaction networks of the DEGs were constructed and the overlapping network was extracted. Finally, the functions and pathways of the DEGs in the overlapping network were enriched. In total, 224 DEGs coexisted in the two genistein groups, and the most significant function of these was the cell cycle. The number and the fold change of expression values of the DEGs in the $10 \mu \mathrm{mol} / 1$ genistein group were significantly higher compared with that of the $3 \mu \mathrm{mol} / 1$ genistein group. The most significant function and pathway of the DEGs in the overlapping network was the cell cycle involving several genes, including GLIPR1, CDC20, BUB1, MCM2 and CCNB1. Thus, genistein stimulation resulted in gene expression changes in breast cancer cell lines and discrepancies increased with higher doses of genistein. The DEGs were most significantly associated with cell cycle regulation.
\end{abstract}

Correspondence to: Dr Tao Zhang, Department of Oncology, Chengdu Military General Hospital, 270 Rongdu Avenue, Jinniu District, Chengdu, Sichuan 610083, P.R. China

E-mail: zhangtao269@126.com

Key words: genistein, breast cancer, differentially expressed genes, cell cycle

\section{Introduction}

Breast cancer, is a major public-health issue worldwide, and is the most common type of cancer in females (1). Approximately $25 \%$ (2) of all females diagnosed with breast cancer succumb to their disease, despite being treated according to the clinical guidelines (3). The causes of breast cancer have been widely investigated to improve disease prevention and diagnosis. Susceptibility to breast cancer has been attributed to a small number of highly penetrant mutations and a large number of low-penetrant variations (4). The mutations of the tumor suppressor genes breast cancer 1 (BRCA1) and BRCA2, have been demonstrated to be closely associated with breast cancer $(5,6)$. However, the complex pathogenesis remains controversial and is under investigation.

Genistein is the simplest isoflavonoid, which exists extensively in the Leguminosae (7), and is often used as a cancer chemopreventive agent. Previous research has demonstrated that genistein can reduce the incidence of diseases that are dependent upon estrogen, and functions in the prevention of tumors, cardiovascular disease and osteoporosis (8). Furthermore, genistein has been demonstrated to be effective in the prevention of chemically induced mammary tumors in rats (9). This has been attributed to the promotion of cell differentiation and inactivation of the epidermal grow th factor signaling pathway (10). Conversely, research has shown that dietary genistein can stimulate mammary gland growth and enhance the growth of MCF-7 cell tumors in ovariectomized athymic mice (11). $\mathrm{A} \geq 10 \mu \mathrm{mol} / 1$ dose of genistein in in vitro experiments has confirmed its effectiveness in breast cancer treatment (12). However, dietary treatment with genistein at physiological concentrations produces blood levels of genistein $(0.39-3.36 \mu \mathrm{mol} / \mathrm{l})$ that are sufficient to stimulate estrogenic effects, such as breast tumor growth (13). Therefore the effects of different concentrations and doses of genistein in the prevention or promotion of breast cancer remain unclear.

The present study investigated the potential mechanism underlying the effects of genistein and the influence of different genistein concentrations on breast cancer. Microarray data analysis was used to compare the gene expression profiles of the MCF-7 human breast cancer cell line, treated with 3 and $10 \mu \mathrm{mol} / \mathrm{l}$ genistein, with MCF-7 cells treated with alcohol. 


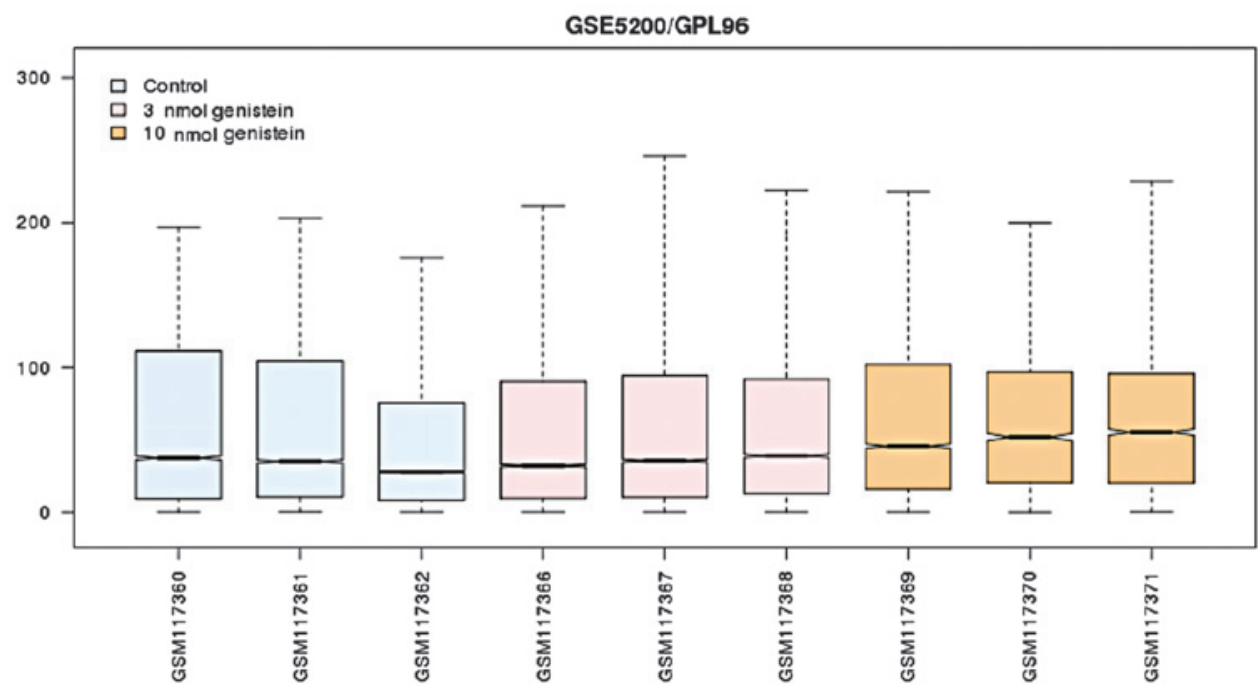

Figure 1. Box-plot of normalized expression data. The control group, 3 and $10 \mu \mathrm{mol} / 1$ genistein groups are represented by blue, pink and orange boxes, respectively. The horizantal black line within the box represents the median, and an equal median indicates an accurate normalization method.

\section{Materials and methods}

Affymetrix microarray data. The gene microarray data of GSE5200 (14), including three MCF-7 human breast cancer cell samples treated with $0.1 \%$ alcohol (control group) for $48 \mathrm{~h}$, three MCF-7 human breast cancer cell samples treated with $3 \mu \mathrm{mol} / 1$ genistein for $48 \mathrm{~h}$ and three MCF-7 human breast cancer cell samples treated with $10 \mu \mathrm{mol} / 1$ genistein for $48 \mathrm{~h}$, were downloaded from the Gene Expression Omnibus (GEO) database (http://www.ncbi.nlm.nih.gov/geo/). The Affymetrix Human Genome U133A Array (GPL96) was applied for the analysis of gene expression profiling, and annotation information for all the probe sets was obtained from Affymetrix (Santa Clara, CA, USA).

Preprocessing of the raw data and differentially expressed gene (DEG) analysis. Data preprocessing and normalization were performed using the Support Vector Regression (15). The raw data of all the samples were converted to an expression profile format. The missing data were then imputed (16), and the complete data were normalized using Support Vector Regression (15). Statistical analysis was performed using the LIMMA (Linear Models for Microarray Data) package in $\mathrm{R}$ language (17) to identify the DEGs in the groups treated with $3 \mu \mathrm{mol} / 1$ and $10 \mu \mathrm{mol} / 1$ genistein compared with the control group. The threshold was set at $\mathrm{P}<0.05$ and $\log \mathrm{FCl}>1$.

Functional enrichment of DEGs. The sequences of the DEGs selected in the 3 and $10 \mu \mathrm{mol} / 1$ genistein groups were mapped using the Clusters of Orthologous Groups (COG) database (http://www.ncbi.nlm.nih.gov/COG) (18) with BLASTX software (19) (similarity threshold, E-value $<1 \mathrm{E}-5$ ), to obtain the functional annotation and COG classification of the DEGs. Through COG classification, the functions of the DEGs in the breast cancer cells treated with different concentrations of genistein, were represented visually and were subsequently analyzed.

Construction of the interaction network. The combination and dissociation of proteins is required for vital physiological activities and the responses of cells to the external and internal environment are based on the signal transduction networks formed by protein-protein interaction (PPI) networks (20). It is therefore necessary to investigate PPI networks to understand biological processes (21). In the present study, the interaction networks of the DEGs in the two groups treated with genistein were constructed using Osprey software (22), which is designed to enhance the understanding of interaction networks and protein complexes. This software is integrated with the Biomolecular Interaction Network Database (BIND) (23) and Global Resource Information Database (GRID) $(23,24)$, which include $>50,000$ interactions among protein and nucleotide sequences. The interaction networks of the two groups were integrated and the overlapping network was abstracted for subsequent analysis.

Functional enrichment analysis of the genes in the overlapping network. Gene set enrichment analysis is based on a group of genes that possess common or relevant functions as compared with the traditional single gene analysis. The variation in biological function is considered to be related to the expression profile of the gene sets rather than individual genes $(24,25)$. In the present study, the DEGs obtained in the overlapping network of the two interaction networks, underwent functional enrichment analysis using the Database for Annotation Visualization and Integrated Discovery (DAVID) (26) software, with a false discovery rate $($ FDR $)<0.05$.

Pathway enrichment of the genes in the overlapping network. The pathway enrichment analysis of the DEGs that were identified in the overlapping network, which was obtained from the two groups treated with 3 and $10 \mu \mathrm{mol} / 1$ genistein respectively, was performed using WebGestalt $(27,28)$ software. The statistical threshold was set to FDR $<0.05$.

\section{Results}

Screening of the DEGs. After preprocessing, the standardized expression profile (Fig. 1) was subjected to differential 


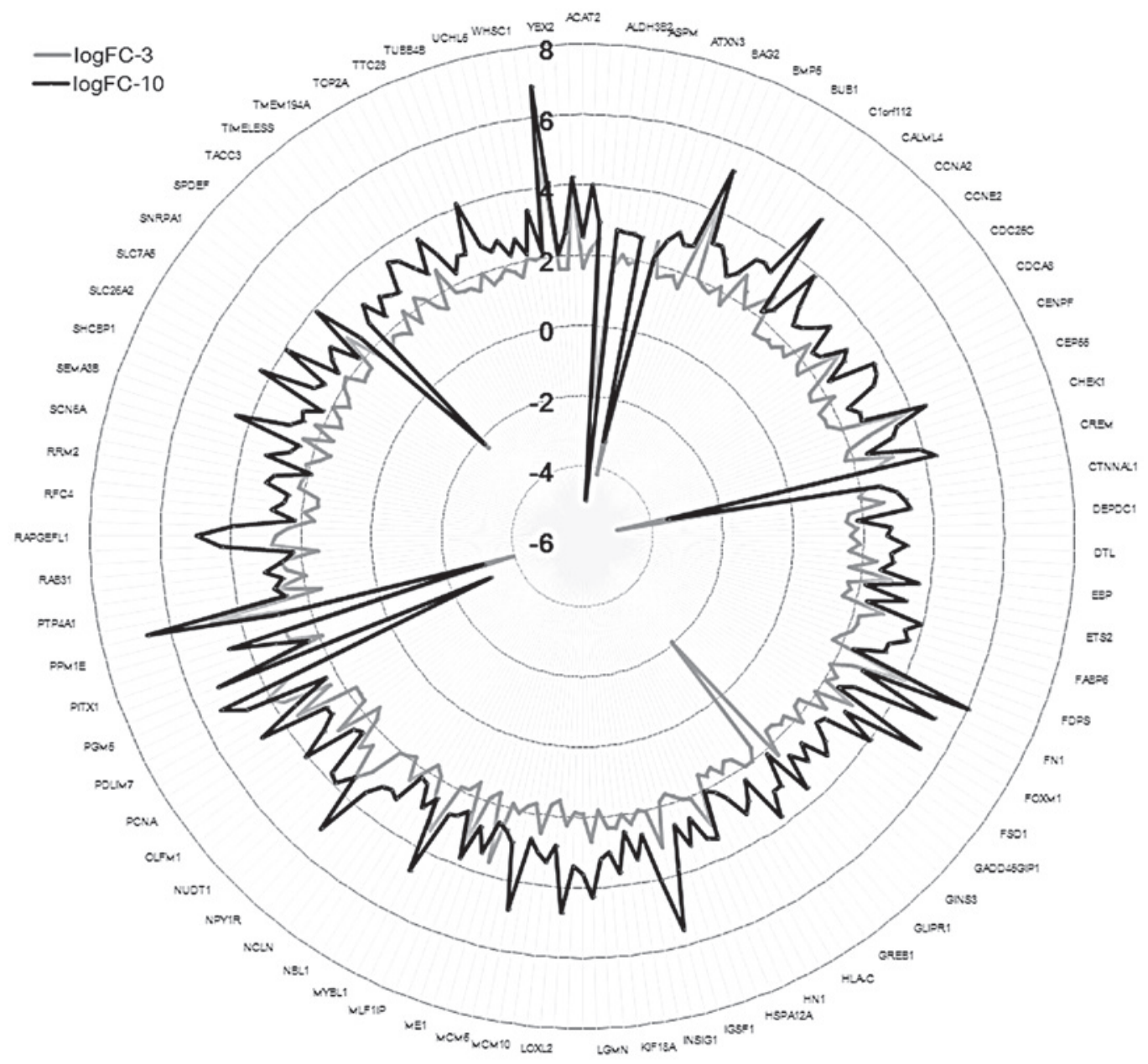

Figure 2. Comparison of the differentially expressed genes identified in the 3 and $10 \mu \mathrm{mol} / 1$ genistein-treated groups.

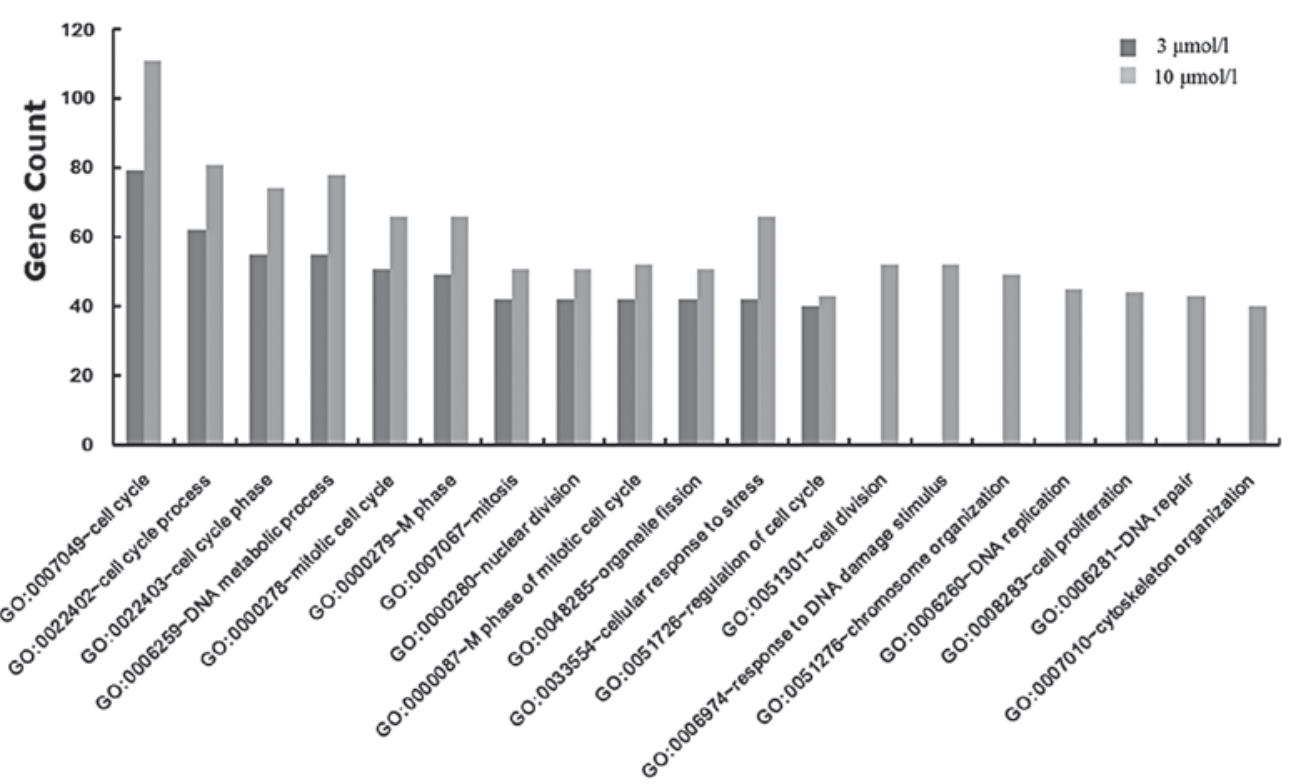

Figure 3. Functional classification of the differentially expressed genes in the two groups treated with $3 \mu \mathrm{mol} / 1$ and $10 \mu \mathrm{mol} / 1$ genistein.

analysis. The results showed that 544 and 729 DEGs were screened out in the 3 and $10 \mu \mathrm{mol} / 1$ genistein group, respectively $(\mathrm{P}<0.05$ and $\log \mathrm{FCl}>1)$. The number of DEGs in the
$10 \mu \mathrm{mol} / \mathrm{l}$ genistein group was markedly greater as compared with that of the $3 \mu \mathrm{mol} / \mathrm{l}$ genistein group. Furthermore, there were 224 DEGs that were present in both groups (Fig. 2). The 


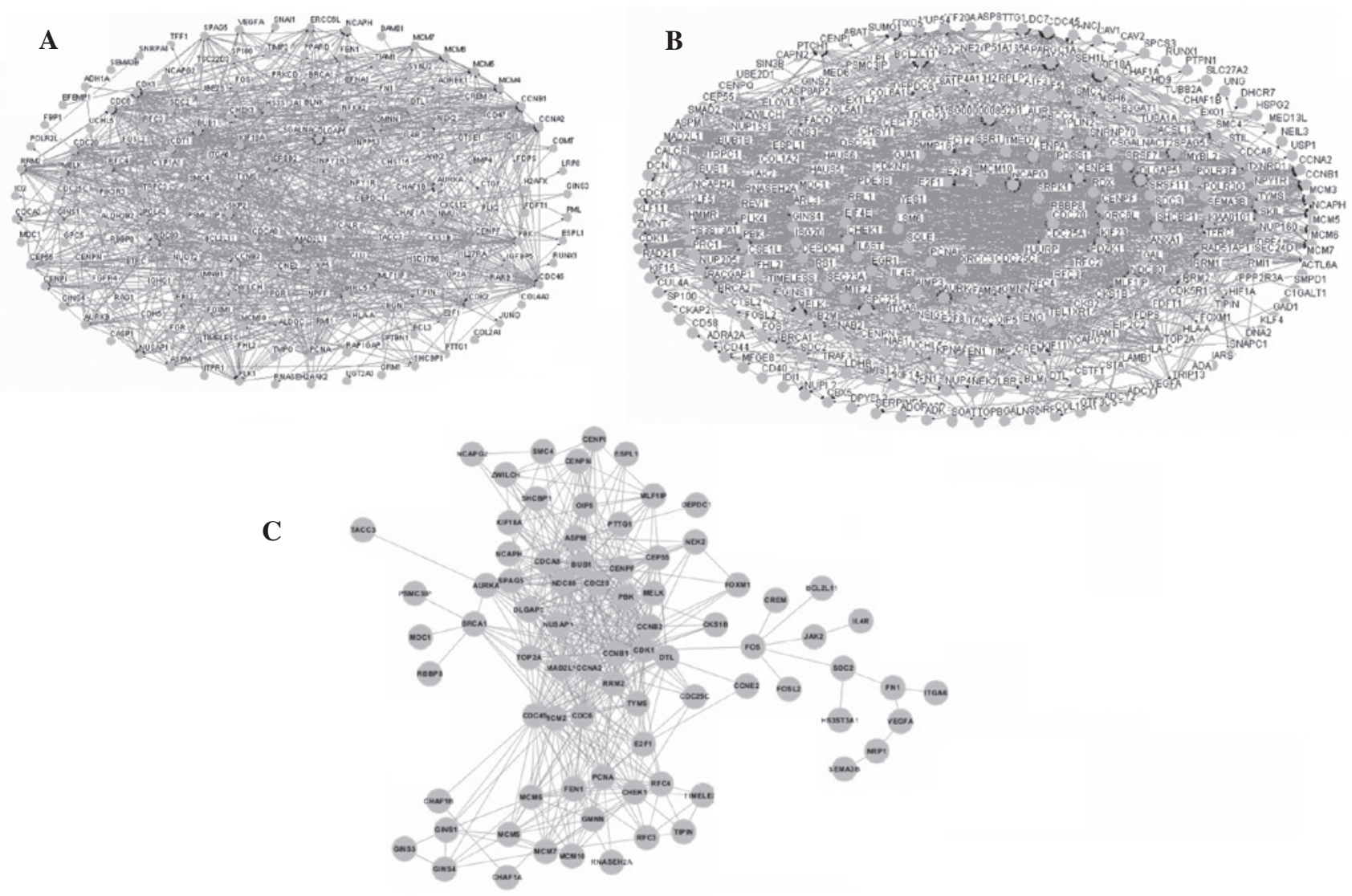

Figure 4. Interaction networks of the differentially expressed genes in the (A) $3 \mu \mathrm{mol} / 1$ and (B) $10 \mu \mathrm{mol} / 1$ genistein group. (C) The overlapping network produced from the two networks.

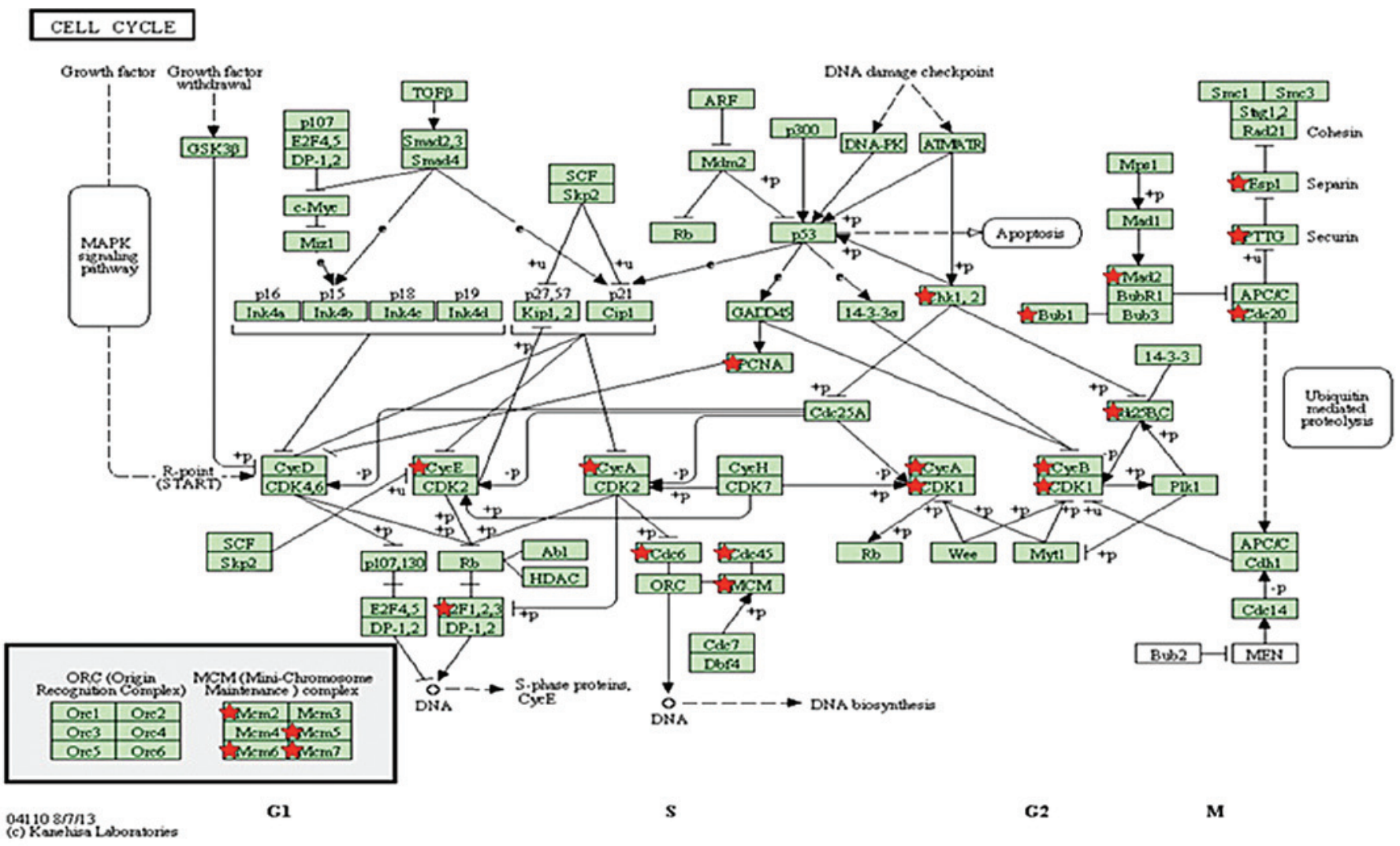

Figure 5. Cell cycle pathway. Red markers represent the differentially expressed genes included in the overlapping network. 
Table I. Result of functional enrichment of differentially expressed genes in the overlapping network.

\begin{tabular}{lll}
\hline Term & Count & FDR \\
\hline GO:0007049 $\sim$ cell cycle & 47 & $4.02 \times 10^{-31}$ \\
GO:0000280 $\sim$ nuclear division & 30 & $1.39 \times 10^{-27}$ \\
GO:0007067 mitosis & 30 & $1.39 \times 10^{-27}$ \\
GO:0000087 M phase of mitotic cell cycle & 30 & $2.39 \times 10^{-27}$ \\
GO:0048285 organelle fission & 30 & $4.64 \times 10^{-27}$ \\
GO:0000279 $\sim$ M phase & 33 & $1.43 \times 10^{-26}$ \\
GO:0006260 $\sim$ DNA replication & 28 & $2.51 \times 10^{-26}$ \\
GO:0022403 cell cycle phase & 35 & $4.92 \times 10^{-26}$ \\
GO:0000278 mitotic cell cycle & 33 & $6.18 \times 10^{-25}$ \\
GO:0022402 $\sim$ cell cycle process & 36 & $9.46 \times 10^{-23}$ \\
GO:0051301 $\sim$ cell division & 29 & $2.00 \times 10^{-22}$ \\
GO:0006259 DNA metabolic process & 33 & $1.14 \times 10^{-20}$ \\
GO:0051726 regulation of cell cycle & 25 & $5.84 \times 10^{-16}$ \\
GO:0006974 response to DNA damage & 20 & $2.95 \times 10^{-9}$ \\
GO:0033554 cellular response to stress & 22 & $7.08 \times 10^{-8}$
\end{tabular}

FDR, false discovery rate.

Table II. Result of pathway enrichment of differentially expressed genes in the overlapping network.

\begin{tabular}{lrr}
\hline Term & Count & FDR \\
\hline hsa04110:Cell cycle & 20 & $1.52 \times 10^{-16}$ \\
hsa03030:DNA replication & 9 & $5.95 \times 10^{-7}$ \\
hsa04114:Oocyte meiosis & 11 & $3.16 \times 10^{-5}$ \\
\hline
\end{tabular}

FDR, false discovery rate.

number and the fold change of expression values of the DEGs in the $10 \mu \mathrm{mol} / 1$ genistein group were significantly higher as compared with the $3 \mu \mathrm{mol} / 1$ genistein group.

Functional enrichment analysis of the DEGs. To determine the function of the DEGs in the two groups treated with genistein, the DEGs were mapped to the COG database. Twelve functional nodes were identified in the group treated with $3 \mu \mathrm{mol} / 1$ genistein, and 19 functional nodes were identified in the group treated with $10 \mu \mathrm{mol} / 1$ genistein (Fig. 3). In the $10 \mu \mathrm{mol} / 1$ genistein group, there were seven functional nodes, which included cell division, DNA damage response, chromosome organization, DNA replication, cellular proliferation, DNA repair and cytoskeleton organization; and 12 functional nodes that were shared in both groups. The most significant function of the DEGs in the $3\left(\right.$ FDR $\left.=3.29 \times 10^{-17}\right)$ and $10 \mu \mathrm{mol} / 1$ genistein groups $\left(\mathrm{FDR}=4.31 \times 10^{-26}\right)$ was the cell cycle (GO:0007049).

Interaction networks of the samples treated with genistein. The interaction networks of the DEGs in the two groups were constructed using Osprey software. The networks of the groups treated with 3 and $10 \mu \mathrm{mol} / 1$ genistein are shown in Fig. 4A and $\mathrm{B}$, respectively. These two networks were merged and the overlapping network was extracted (Fig. 4C). The overlapping network consisted of 49 DEGs and 499 edges.

Functional enrichment analysis of the genes in the overlapping network. In order to investigate the potential functions of the DEGs, the 49 DEGs were subjected to functional enrichment analysis using DAVID software. The results indicated that the 49 genes clustered into 15 functional terms (Table I), including the cell cycle $\left(\mathrm{FDR}=4.02 \times 10^{-31}\right)$, nuclear division $\left(\mathrm{FDR}=1.39 \times 10^{-27}\right)$ and mitosis $\left(\mathrm{FDR}=1.39 \times 10^{-27}\right)$. The most significant function was the cell cycle (GO:0007049, $\mathrm{FDR}=4.02 \times 10^{-31}$ ), which contained 47 genes, including cell division cycle 20 (CDC20), spindle checkpoint gene (BUB1), mini-chromosome maintenance (MCM) complex 2 and cyclin B1 (CCNB1).

Pathway enrichment of the genes in the overlapping network. In order to understand the pathway and function of the DEGs in the overlapping network, the 49 DEGs underwent pathway enrichment analysis using the WebGestalt software. The results (Table II) indicated that three pathways were significantly enriched, including the cell cycle (FDR $\left.=1.52 \times 10^{-16}\right)$, DNA replication $\left(\mathrm{FDR}=5.95 \times 10^{-7}\right)$ and oocyte meiosis $\left(\mathrm{FDR}=3.16 \times 10^{-5}\right)$. The cell cycle was the most significant pathway, containing 
20 DEGs (Fig. 5), including CDC20, MCM2, CCNB1 and BUB1. These data indicated that the DEGs were involved in different phases of the cell cycle.

\section{Discussion}

Breast cancer is the most commonly diagnosed type of cancer among females. Although certain genetic mutations have demonstrated an association with the development of breast cancer, such as p53 and BRCA1 $(29,30)$, there remain numerous unanswered questions regarding the etiology of this disease (31).

In the present study, the gene expression profiles of MCF 7 cells treated with 3 and $10 \mu \mathrm{mol} / 1$ genistein were analyzed, respectively. The results showed that the number of DEGs in the cell cycle was increased in the $10 \mu \mathrm{mol} / \mathrm{l}$ genistein group as compared with the $3 \mu \mathrm{mol} / \mathrm{l}$ genistein group, and the function of cell proliferation was enriched in the $10 \mu \mathrm{mol} / 1$ genistein group. This suggested that a high concentration of genistein could initiate more marked changes in the expression of the DEGs. The most significant function of the DEGs in the overlapping network was the cell cycle, involving 47 DEGs, including CDC20, BUB1, MCM2 and cyclin B1. These genes were also involved in the cell cycle pathway, which was the most significant pathway in the pathway enrichment analysis. CDC20 is an essential cell-cycle regulator required for the completion of mitosis. CDC20 binds to and activates the ubiquitin ligase activity of the anaphase-promoting complex/cyclosome (APC/C), and enables the ubiquitination and degradation of securin and cyclin $\mathrm{B}$, thus promoting the onset of anaphase and completion of mitotis (32). The mRNA and protein levels of CDC20 and BUB1 have been shown to be significantly higher in breast cancer cell lines and in high-grade primary breast cancer tissues. In addition, the upregulation of BUB1 protein is used as a marker, as it is upregulated in $\sim 80 \%$ of breast cancers in paraffin-embedded tissues (33). Upregulation of cyclin B1 has been associated with poor prognosis in hormone receptor-positive, luminal B and basal-like breast cancers (34). MCM-2 has been reported for its use as a strongly independent prognostic marker in breast cancer and non-small cell lung cancer $(35,36)$, in addition to the standard proliferation marker Ki-67. MCM2 and BUB1 have additionally been identified to be involved in cell cycle progression (37). Therefore, the cell cycle may be important role in the development of breast cancer. In this study, the expression levels of CDC20, BUB1, MCM2, and cyclin B1 were upregulated in the 3 and $10 \mu \mathrm{mol} / 1$ genistein groups, indicating the promoting effects of genistein on cancer cell proliferation. However, inhibition effects of genistein on cancer cell proliferation also exist and act via the cell cycle.

Pathway enrichment analysis further confirmed the participation of these DEGs in the cell cycle. Cell cycle arrest caused by genistein occurs during different phases of the cell cycle, including $\mathrm{G}_{2} / \mathrm{M}, \mathrm{G}_{0} / \mathrm{G}_{1}$ and $\mathrm{G}_{1} / \mathrm{S}$ phase. In a previous study, Cappelletti et al (38) demonstrated that genistein could restrain breast cancer cells to the $\mathrm{G}_{2} / \mathrm{M}$ phase (38). The accumulation of genistein-treated cells have additionally been shown to exist in the $S$ and $\mathrm{G}_{2} / \mathrm{M}$ phases of the cell cycle, and undergo apoptosis (39). Genistein could induce the up- and downregulation of apoptosis-associated genes, including
Bax-2, p21WAF1, Bcl-2 and p53 (40), and the ratio of Bax and Bcl-2 were previously demonstrated to be important for the survival of cells (41). Therefore, genistein could inhibit the cell cycle in breast cancer, resulting in cellular apoptosis. Notably, the GLIPR1 gene was downregulated in the $3 \mu \mathrm{mol} / 1$ genistein group, while upregulated in the $10 \mu \mathrm{mol} / 1$ genistein group. GLIPR1, also termed RTVP1, encodes glioma pathogenesis-related protein 1, which has p53-regulated proapoptotic activities, and is downregulated in prostate and bladder cancer cells (42). The discrepancy in the GLIPR1 expression between the two genistein groups indicated that the effects of genistein are dose-dependent, and genestien only inhibits cancer at a high concentration.

In conclusion, the cell cycle may be an important pathway based on the analysis of MCF-7 breast cancer cells treated with 3 and $10 \mu \mathrm{mol} / 1$ genistein, respectively. This revealed that the cell cycle may be an important pathway in the mechanisms underlying the treatment of breast cancer with genistein. The identified DEGs, which were involved in cell cycle, including CDC20, BUB1, GLIPR1, MCM2, and CCNB1, could have a crucial function in the development of breast cancer, and may become potential targets or prognostic markers for breast cancer. Experimental verification is required in future studies.

\section{Acknowledgements}

The authors would like to thank the Applied Basic Research Program of Science \& Technology Department of Sichuan for funding this research (grant no. 2011JY0038).

\section{References}

1. Jemal A, Siegel R, Xu J and Ward E: Cancer statistics, 2010. CA Cancer J Clin 60: 277-300, 2010.

2. Brenner H: Long-term survival rates of cancer patients achieved by the end of the 20th century: a period analysis. Lancet 360 : $1131-1135,2002$.

3. Goldhirsch A, Glick JH, Gelber RD, Coates AS and Senn HJ: Meeting highlights: International consensus panel on the treatment of primary breast cancer. Seventh international conference on adjuvant therapy of primary breast cancer. J Clin Oncol 19: 3817-3827, 2001.

4. Nathanson KL, Wooster R and Weber BL: Breast cancer genetics: what we know and what we need. Nat Med 7: 552-556, 2001.

5. Rahman N and Stratton MR: The genetics of breast cancer susceptibility. Annu Rev Genet 32: 95-121, 1998.

6. King MC, Marks JH and Mandell JB; New York Breast Cancer Study Group: Breast and ovarian cancer risks due to inherited mutations in BRCA1 and BRCA2. Science 302: 643-646, 2003.

7. Dixon RA and Ferreira D: Genistein. Phytochemistry 60: 205-211, 2002.

8. Marini H, Minutoli L, Polito F, et al: Effects of the phytoestrogen genistein on bone metabolism in osteopenic postmenopausal women: a randomized trial. Ann Intern Med 146: 839-847, 2007.

9. Fritz WA, Coward L, Wang J and Lamartiniere CA: Dietary genistein: perinatal mammary cancer prevention, bioavailability and toxicity testing in the rat. Carcinogenesis 19: 2151-2158, 1998.

10. Lamartiniere CA: Protection against breast cancer with genistein: a component of soy. Am J Clin Nutr 71 (Suppl): 1705S-1709S, 2000.

11. Hsieh CY, Santell RC, Haslam SZ and Helferich WG: Estrogenic effects of genistein on the growth of estrogen receptor-positive human breast cancer (MCF-7) cells in vitro and in vivo. Cancer Res 58: 3833-3838, 1998.

12. Messina MJ and Loprinzi CL: Soy for breast cancer survivors: a critical review of the literature. J Nutr 131 (Suppl): 3095S-3108S, 2001. 
13. Ju YH, Allred CD, Allred KF, Karko KL, Doerge DR and Helferich WG: Physiological concentrations of dietary genistein dose-dependently stimulate growth of estrogen-dependent human breast cancer (MCF-7) tumors implanted in athymic nude mice. J Nutr 131: 2957-2962, 2001.

14. Shioda T, Chesnes J, Coser KR, et al: Importance of dosage standardization for interpreting transcriptomal signature profiles: evidence from studies of xenoestrogens. Proc Natl Acad Sci USA 103: 12033-12038, 2006.

15. Fujita A, Sato J, Rodrigues Lde O, Ferreira CE and Sogayar MC: Evaluating different methods of microarray data normalization. BMC Bioinformatics 7: 469, 2006.

16. Troyanskaya O, Cantor M, Sherlock G, et al: Missing value estimation methods for DNA microarrays. Bioinformatics 17 520-525, 2001

17. Smyth GK: Limma: linear models for microarray data. In: Bioinformatics and Computational Biology Solutions Using R and Bioconductor. Gentleman R, Carey V, Dudoit $\mathrm{S}$, Irizarry R and Huber W (eds). Springer, New York, NY, pp397-420, 2005.

18. Tatusov RL, Natale DA, Garkavtsev IV, et al: The COG database: new developments in phylogenetic classification of proteins from complete genomes. Nucleic Acids Res 29: 22-28, 2001.

19. Altschul SF, Gish W, Miller W, Myers EW and Lipman DJ: Basic local alignment search tool. J Mol Biol 215: 403-410, 1990

20. Giot L, Bader JS, Brouwer C, et al: A protein interaction map of Drosophila melanogaster. Science 302: 1727-1736, 2003.

21. Deng M, Zhao JY, Ju XD, Tu PF, Jiang Y and Li ZB: Protective effect of tubuloside $\mathrm{B}$ on TNFalpha-induced apoptosis in neuronal cells. Acta Pharmacol Sin 25: 1276-1284, 2004.

22. Breitkreutz B-J, Stark C and Tyers M: Osprey: a network visualization system. Genome Biol 4: R22, 2003.

23. Willis RC and Hogue CW: Searching, viewing, and visualizing data in the Biomolecular Interaction Network Database (BIND). Curr Protoc Bioinformatics: Chapter 8: Unit 8.9, 2006.

24. Breitkreutz BJ, Stark C and Tyers M: The GRID: the General Repository for Interaction Datasets. Genome Biol 4: R23, 2003.

25. Nam D and Kim SY: Gene-set approach for expression pattern analysis. Brief Bioinform 9: 189-197, 2008.

26. Huang da W, Sherman BT and Lempicki RA: Systematic and integrative analysis of large gene lists using DAVID bioinformatics resources. Nat Protoc 4: 44-57, 2009.

27. Zhang B, Kirov S and Snoddy J: WebGestalt: an integrated system for exploring gene sets in various biological contexts. Nucleic Acids Res 33: W741-W748, 2005.
28. Duncan D, Prodduturi N and Zhang B: WebGestalt2: an updated and expanded version of the Web-based Gene Set Analysis Toolkit. BMC Bioinformatics 11: P10, 2010.

29. Coles C, Condie A, Chetty U, Steel CM, Evans HJ and Prosser J: p53 mutations in breast cancer. Cancer Res 52: 5291-5298, 1992.

30. Giancotti V: Breast cancer markers. Cancer Lett 243: 145-159, 2006.

31. Ganz PA: Breast cancer, menopause, and long-term survivorship: critical issues for the 21st century. Am J Med 118: 136-141, 2005.

32. Yu H: Cdc20: A WD40 activator for a cell cycle degradation machine. Mol Cell 27: 3-16, 2007.

33. Yuan B, Xu Y, Woo JH, et al: Increased expression of mitotic checkpoint genes in breast cancer cells with chromosomal instability. Clin Cancer Res 12: 405-410, 2006.

34. Agarwal R, Gonzalez-Angulo AM, Myhre S, et al: Integrative analysis of cyclin protein levels identifies cyclin b1 as a classifier and predictor of outcomes in breast cancer. Clin Cancer Res 15: 3654-3662, 2009.

35. Gonzalez MA, Pinder SE, Callagy G, et al: Minichromosome maintenance protein 2 is a strong independent prognostic marker in breast cancer. J Clin Oncol 21: 4306-4313, 2003.

36. Yang J, Ramnath N, Moysich KB, et al: Prognostic significance of MCM2, Ki-67 and gelsolin in non-small cell lung cancer. BMC Cancer 6: 203, 2006.

37. Sotiriou C, Neo SY, McShane LM, et al: Breast cancer classification and prognosis based on gene expression profiles from a population-based study. Proc Natl Acad Sci USA 100: 10393-10398, 2003.

38. Cappelletti V, Fioravanti L, Miodini P and Di Fronzo G: Genistein blocks breast cancer cells in the $\mathrm{G}(2) \mathrm{M}$ phase of the cell cycle. J Cell Biochem 79: 594-600, 2000.

39. Fioravanti L, Cappelletti V, Miodini P, Ronchi E, Brivio M and Di Fronzo G: Genistein in the control of breast cancer cell growth: insights into the mechanism of action in vitro. Cancer Lett 130: 143-152, 1998 .

40. Li Y, Upadhyay S, Bhuiyan M and Sarkar FH: Induction of apoptosis in breast cancer cells MDA-MB-231 by genistein. Oncogene 18: 3166-3172, 1999.

41. Salomons GS, Brady HJ, Verwijs-Janssen M, et al: The Bax alpha:Bcl-2 ratio modulates the response to dexamethasone in leukaemic cells and is highly variable in childhood acute leukaemia. Int J Cancer 71: 959-965, 1997.

42. Ren C, Li L, Yang G, et al: RTVP-1, a tumor suppressor inactivated by methylation in prostate cancer. Cancer Res 64: 969-976, 2004 